\title{
PEMANASAN DALAM BENTUK PERMAINAN PADA PEMBELAJARAN PERMAINAN SEPAKBOLA DI SEKOLAH DASAR
}

Oleh: Yudanto

Dosen Jurusan Pendidikan Olaharaga FIK UNY

\section{Abstrak}

Pemanasan merupakan kegiatan awal dalam
setiap kegiatan olaharaga pembelajaran. Pemanasan akan memberikan kesan kepada siswa terhadap kegiatan yang akan dilakukan berikutnya. Di dalam pembelajaran permainan Sepakbola di Sekolah Dasar, harus didahului dengan pemanasan. Pemanasan yang diberikan dalam pembelajaran sepakbola dapat dikemas dalam bentuk permainan.

Pemanasan dalam bentuk permainan ini, akan memberikan kesan yang menarik kepada siswa, sehingga akan membuat siswa siap secara fisik dan mental untuk mengikuti kegiatan pembelajaran permainan sepakbola selanjutnya. Salah satu contoh pemanasan dalam bentuk permainan untuk pembelajaran permainan sepakbola di Sekolah Dasar adalah "Permainan Berburu Kijang". Pemanasan yang dilakukan selama 10-15 menit ini, selain bertujuan untuk menyiapkan fisik dan mental siswa juga mengembangkan teknik dasar bermain sepakbola.

Kata kunci: Pemanasan dalam Bentuk Permainan, Pembelajaran Sepakbola di Sekolah Dasar 
Permainan sepakbola merupakan salah satu permainan bola besar yang diajarkan di Sekolah Dasar mulai dari kelas IV-VI. Materi permainan sepakbola yang diajarkan dalam mata pelajaran Pendidikan Jasmani, Olahraga dan Kesehatan, pada dasarnya merupakan sarana yang digunakan dalam proses pendidikan. Materi permainan sepakbola yang diajarkan di Sekolah Dasar, harus disesuaikan dengan tahap pertumbuhan dan perkembangan anak. Materi permainan sepakbola bagi siswa Sekolah Dasar, harus diberikan dalam bentuk yang berbeda. Bentuk permainan sepakbola yang diberikan bagi siswa Sekolah Dasar, tidak boleh disamakan dengan bentuk materi permainan sepakbola bagi orang dewasa. Menurut Yuanita Nasution (2000: 68) menyatakan bahwa sebelum memberikan aktivitas fisik atau olahraga yang sesuai bagi anak usia dini (6-14 tahun), sebaiknya harus mengetahui dan disesuaikan dengan karakteristik pertumbuhan dan perkembangan anak, baik pertumbuhan fisik, maupun mental emosionalnya. Lebih lanjut menurut Agus Mahendra (2003) menyatakan bahwa ruang lingkup Pendidikan Jasmani yang ditawarkan di sekolah dasar semestinya dikembangkan berdasarkan kebutuhan anakanak, serta memperhatikan beberapa pertimbangan diantaranya: (1) dasar-dasar pengembangan program, (2)

MEDIKORA Vol.III, No 1, April 2007: 288-302 
pola pertumbuhan dan perkembangan anak, (3) dorongan dasar anak-anak, dan (4) karakteristik serta minat anak. Permainan sepakbola yang diberikan bagi anak-anak atau siswa Sekolah Dasar seharusnya diberikan dalam bentuk permainan yang di modifikasi. Lebih lanjut menurut Gusril (2004: 45) menyatakan bahwa modifikasi olahraga dalam Pendidikan Jasmani sangat diperlukan khususnya bagi anakanak, hal ini dikarenakan anak-anak (siswa) secara fisik dan emosional belum matang, jika dibandingkan dengan orang dewasa.

Pada dasarnya dalam setiap proses pembelajaran cabang olahraga baik dalam cabang olahraga senam, atletik, maupun permainan, selalu diawali dengan pemanasan. Pemanasan berguna untuk menghangatkan suhu otot, melancarkan aliran darah dan memperbanyak masuknya oksigen ke dalam tubuh, memperbaiki kontraksi otot dan kecepatan gerak reflek, juga untuk mencegah kejang otot. Pemanasan sebagai awal kegiatan dalam setiap pembelajaran olahraga. Di dalam pembelajaran, pemanasan memberikan peranan yang amat penting untuk membawa anak atau menanamkan kesan pertama kepada siswa tentang apa yang akan dilakukan pada inti pembelajaran. 
Di dalam pembelajaran permainan sepakbola di Sekolah Dasar, tidak ada salahnya seorang guru memberikan pemanasan pada siswanya dalam bentuk pemanasan lari mengelilingi lapangan, kemudian dilanjutkan gerakan peregangan (gerakan statis), dan gerakan dinamis. Bentuk pemanasan seperti ini tentu memberikan kesan pada siswanya. Menurut Joe Luxbacher (2004: 1) menyatakan bahwa pemanasan dalam sepakbola, yang menggunakan bentuk pemanasan tradisional, seperti kegiatan peregangan atu bentuk pemanasan jumping jack, sit up, push up dan kne bend, akan terasa kurang menimbulkan gereget/minat dalam mengikuti latihan. Kondisi semacam ini haruslah dihindari, agar selama proses pembelajaran sepakbola dapat diikuti oleh siswa dengan penuh keseriusan tidak bosan, sehingga tujuan pembelajaran yang diinginkan dapat tercapai.

\section{HAKEKAT DAN TUJUAN PEMANASAN}

Pemanasan merupakan tahapan kegiatan yang dilakukan siswa dalam mengikuti suatu pembelajaran olahraga. Pemanasan memilki peran yang sangat penting bagi siswa, sebelum masuk dalam kegiatan inti ketika mengikuti pembelajaran. Menurut Len Kravits, (1997: 142) pemanasan adalah persiapan aktivitas pertama dari latihan olaharaga,

MEDIKORA Vol.III, No 1, April 2007: 288-302 
untuk mempersiapkan tubuh melakukan latihan-latihan yang lebih keras/berat berikutnya, dan berguna untuk mengurangi cederal Menurut Sukadiyanto (2005: 20) menyatakan ada minimal empat macam kegiatan pada tahap pemanasan, anatara lain: (1) aktivitas yang bertujuan untuk menaikkan suhu badan, (2) aktivitas peregangan (strectching), baik pasif maupun yang aktif (kalestenik/balistik), (3) aktivitas senam khusus cabang olaharaganya, dan (4) aktivitas gerak teknik cabang olaharaganya.

Lebih lanjut menurut Tjaliek Soegiardo (1992: 111) menyatakan bahwa pemanasan merupakan persiapan menjelang melakukan aktivitas. Pemanasan berguna untuk mencegah cedera, disamping itu juga organ tubuh pun dipersiapkan untuk menunjang aktivitas. Perubahan pada organ tubuh yang meliputi jantung, paru-paru, otot dan syaraf hanya bersifat sementara/sesaat dan akan kembali lagi pada keadaan semula. Di lihat dari sudut fisiologis bahwa pemanasan berguna sekali, sebab pemanasan akan menimbulkan panas yang menguntungkan kerja otot, jumlah asam laktat sedikit menyebabkan pembuluh darah otot melebar, kadar $\mathrm{CO} 2$ menurun memacu pernapasan agar siap dan penurunan kadar $\mathrm{O} 2$ dan panas memacu jantung berdenyut cepat dan kuat. 
Pemanasan sebelum berolahraga dapat membuat: (1) meningkatkan aliran darah ke jaringan tubuh sehingga otot lebih lentur, (2) meningkatkan pengiriman oksigen dan nutrisi ke otot dengan meningkatkan aliran darah, (3) Menyiapkan otot untuk peregangan, (4) menyiapkan jantung untuk meningkatkan aktivitas, (5) menyiapkan secara mental untuk olahraga yang akan dilakukan, dan (6) membuat jalur syaraf ke otot siap berolahraga, (http://victorhealth.blogspot.com/2008/10/olahraga-perlu-pemanasandan.html). Beberapa manfaat melakukan pemanasan adalah sebagai berikut: (1) meningkatkan suhu tubuh beserta jaringan-jaringannya., (2) menaikkan aliran darah melalui otot-otot aktif, (3) meningkatkan detak jantung sehingga dapat mempersiapkan bekerjanya sistem jantung dan pembuluh darah (cardiovaskular), (4) menaikkan tingkat energi yang dikeluarkan oleh metabolisme tubuh, meningkatkan pertukaran (pengikatan) oksigen dalam hemoglobin, (6) meningkatkan kecepatan perjalanan sinyal saraf yang memerintah gerakan tubuh, (7) meningkatkan efisiensi dalam proses reciprocal innervation, sehingga memudahkan otot-otot berkontraksi dan rileks secara lebih cepat dan efisien, (8) meningkatkan kapasitas kerja fisik atlet, (9) mengurangi adanya ketegangan pada otot,

MEDIKORA Vol.III, No 1, April 2007: 288-302 
meningkatkan kemampuan jaringan penghubung dalam gerakan memanjang atau meregang, dan (11) terjadi peningkatan kondisi tubuh atlet secara psikologis. http://mp.brawijaya.ac.id/art/04-artikel3.php

Menurut Joe Luxbacher (2004:1) menyatakan bahwa pemanasan berguna untuk menghangatkan suhu otot, melancarkan peredaran aliran darah dan memperbanyak aliran oksigen ke dalam tubuh, memperbaiki kontraksi otot dan kecepatan gerakan reflek, dan juga untuk mencegah kejang otot. Lebih lanjut menurut Bompa (1994) menyatakan bahwa sebagai akibat dari pemanasan adalah: (1) suhu tubuh akan meningkat yang merupakan salah satu faktor yang memudahkan dalam latihan atau pertandingan, pemanasan akan merangsang aktivitas sistem syaraf pusat yang mengkoordinasikan sistem organisasi, dan mempercepat waktu reaksi motorik dan memperhatikan koordinasi tubuh. Oleh sebab itu, pemain dapat memperbaiki unjuk kerja motoriknya. Selain itu, selama pemanasan, pemain akan dapat memotivasi dirinya atau dimotivasi pelatihnya dalam menghadapai pertandingan yang berat, sehingga secara psikologis pemain telah siap untuk mengahdapi latihan ataupun pertandingan yang harus dilaksanakannya. 


\section{PEMANASAN SEPAKBOLA DALAM BENTUK PERMAINAN}

Pemanasan dalam permainan sepakbola dapat dilakukan \melalui lari keliling lapangan, melakukan persegangan otot dengan gerakan statis dan dinamis. Bentukbentuk pemanasan tersebut di atas, tidak ada salahnya digunakan dalam pembelajaran permainan sepakbola bagi siswa di Sekolah Dasar. Bentuk pemasanan yang menarik sangat penting untuk diberikan supaya siswa dalam melakukan pemanasan secara sungguh-sungguh. Bentuk pemanasan dalam permainan, merupakan salah satu bentuk pemanasan yang dapat digunakan sebelum pembelajaran permainan sepakbola di Sekolah Dasar. Menurut Agus Mahendra (2001: 128) menyatakan bahwa ketika anak-anak melakukan pemanasan yang menarik, dapat diduga bahwa secara fisik dan mental anak akan siap untuk mengikuti pembelajaran. Kesiapan mereka ditandai oleh semangat mereka yang meningkat naik akibat kegiatan pemanasan. Dalam hal tertentu, pemanasan dalam bentuk permainan juga mengandung tuntutan untuk bertindak dan berpikir analitis, dikaitkan dengan pola lingkungan dan pola-pola pergerakan pesertanya. Setiap anak yang terlibat dalam permainan seolah dikondisikan untuk secara cermat mengolah rangsang lingkungan di dalam otaknya untuk

MEDIKORA Vol.III, No 1, April 2007: 288-302 
memberikan respon yang tepat. Melalui ini, tidak ada satu anak pun yang terlibat dalam kegiatan itu tanpa merasa terlibat secara keseluruhan pribadinya. Di samping itu, siswa yang mengikuti pemanasan dalam bentuk permainan, kesigapannya juga meningkat drastis. Hal ini dikarenakan kondisi siswa akan lebih siap secara fisik untuk melakukan aktivitas yang cukup berat sekalipun,

Pemanasan dalam bentuk permainan biasanya mengandung unsur gerak yang cepat, baik yang berbasis lari atau melompat, maupun yang berbasis gerakan melempar maupun menangkap (Agus Mahendra, 2001: 130). Oleh karena itu, permainan apapun yang dilakukan, akan menuntut pesertanya untuk bergerak cepat dan bersifat terus menerus. Pengaruh yang ditimbulkan oleh si anak, akan berkembangnya kemampuan dalam hal kecepatan dan kekuatannya, serta tidak kalah pentingnya adalah kelincahan dan daya tahannya, termasuk daya tahan kecepatan (speed endurance).

Pelaksanaan pemanasan dalam setiap pembelajaran, harus memperhatikan petunjuk pelaksanaan pemanasan. Menurut Agus Mahendara (2001: 130-131) menyatakan bahwa secara umum hendaknya pemanasan mengikuti pedoman sebagai berikut: (1) pemanasan cukup dilakukan 
sekitar 10 menit, (2) pilihlah kegiatan yang mudah di atur dan melibatkan semua anak dalam waktu yang sama, variasikan setiap kegiatan pemanasan dengan memperkenalkan satu atau beberapa kegiatan baru, dan (4) berhentilah pada puncak kegiatan sehingga peserta akan kembali antusias pada pelajaran berikutnya.

\section{PRINSIP-PRINSIP PEMILIHAN PERMAINAN}

Pemilihan permainan yang akan diberikan kepada anak hendaknya perlu memperhatikan beberapa pertimbangan. Menurut Pangrazi (1989: 487) apabila seorang guru dalam memilih dan mengevaluasi sebuah permainan yang akan diberikan kepada anak, perlu memperhatikan beberapa hal diantaranya: keterampilan yang diperlukan, jumlah anak yang ikut atau berpartisipasi, kompleksitas, panjangnya/lamanya permainan, dan kemajuan. Anak harus menerima umpan balik yang positif dari pengalaman permainan yang dilakukan. Apabila dalam melakukan permainan, anak merasa bosan dan tidak senang, maka evaluasi segera dilakukan untuk mengetahui kelemahan dan kekurangan permainan tersebut. Selanjutnya menurut Gabbard (1987: 368) menyatakan bahwa dalam memilih 
sebuah permainan, perlu memperhatikan poin-poin yang harus diterapkan. Poin-poin tersebut diantaranya:

1. Permainan harus bersifat menyenangkan.

2. Permainan harus menyediakan aktivitas untuk semua anak secara maksimal.

3. Meningkatkan pengembangan keterampilan gerak yang dibutuhkan, dan atau mengembangkan serta memilhara kebugaran.

4. Mencakup keseluruhan peserta dan bukan pengurangan peserta permainan.

Gabbard (1987: 368) menyatakan bahwa diperlukan beberapa tambahan sebagai petunjuk dan pertimbangan dalam memilih permainan, yang diantaranya:

1. Penggunaan kemajuan permainan, dari bentuk permainan yang kecil kemudian ke sebuah tim permainan.

2. Ketika melakukan pemilihan permainan, diperlukan peningkatan / kemajuan jumlah dan kompleksitas peraturan serta strategi.

3. Menggunakan situasi permainan untuk evaluasi dan meningkatkan perilaku afektif dan juga kecakapan keterampilan gerak.

4. Keamanan harus sebagai dasar yang harus dipertimbangkan. 
5. Tempatkan anak ke dalam sebuah formasi dan buatlah petunjuk bila dimungkinkan.

6. Meskipuh partisipasi sangat ditekankan, jika partisipasi anak perlu dikurangi, disarankan hanya hanya satu atau dua putaran.

7. Hindari penekanan yang berlebihan dalam sebuah kompetisi.

\section{CONTOH PEMANASAN DALAM BENTU PERMAINAN}

1. Lari keliling lapangan 2 kali putaran.

2. Pemanasan dalam bentuk bermain.

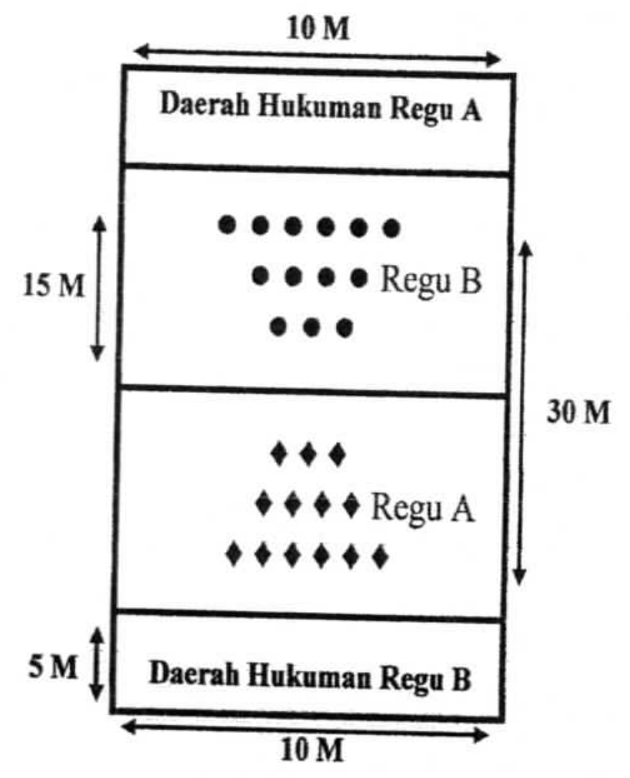

Gambar 1. permainan untuk pemanasan. 


\begin{tabular}{|c|c|}
\hline Nama & Permainan Berburu Kijang \\
\hline Tujuani & $\begin{array}{l}\text { Menghangatkan suhu otot, menyiapkan } \\
\text { siswa baik secara jasmani maupun rohani, } \\
\text { meningkatkan ketangkasan dan kelincahan } \\
\text { gerak, serta mengembangkan teknik dasar } \\
\text { bermain sepakbola. }\end{array}$ \\
\hline $\begin{array}{l}\text { Alat dan } \\
\text { Fasilitas }\end{array}$ & $\begin{array}{l}\text { - Lapangan ukuran } 10 \text { × } 30 \text { meter } \\
\text { - Bola plastik } 6 \text { buah } \\
\text { - Cones } 10 \text { buah } \\
\text { - Kapur putih }\end{array}$ \\
\hline $\begin{array}{l}\text { Jumlah } \\
\text { pemain }\end{array}$ & 16-20 siswa. \\
\hline $\begin{array}{l}\text { Lama } \\
\text { permainan }\end{array}$ & 8-10 menit \\
\hline
\end{tabular}

\section{Peraturan permainan :}

Siswa dibagi menjadi 2 regu dengan jumlah yang sama. Masing-masing regu ditempatkan seperti pada gambar. Masing-masing regu diberikan 3 buah bola. Setiap regu berusaha saling menendang bola ke arah pemain regu lawan. Apabila salah satu pemain lawan kena tembakan pada daerah bagian kaki sampai tungkai atas, maka pemain tersebut mati 
dan harus menempati di daerah hukuman sesuai regunya seperti pada gambar di atas. Pemain yang sudah mati, berusaha imembantu regunya yaitu menembak bola ke arah kaki pemain regu lawan dari daerah yang telah ditentukan. Salah satu regu dianggap kalah dalam permainan ini, apabila semua pemain terkena tembakan lebih cepat/awal daripada regu lawannya.

\section{KESIMPULAN}

Pemanasan berguna untuk menghangatkan suhu otot, melancarkan peredaran aliran darahdan memperbanyak aliran oksigen ke dalam tubuh, memperbaiki kontraksi otot dan kecepatan gerakan reflek, dan juga untuk mencegah kejang otot. Di dalam pemanasan pembelajaran permainan sepakbola di Sekolah Dasar dapat dilakukan dengan gerakan peregangan (gerakan statis), gerakan dinamis, atau dalam bentuk permainan.

Pemanasan dalam bentuk permainan dapat membuat siswa bersungguh-sungguh untuk melakukan pemasanan. Pemanasan ini sangat menarik bagi siswa, sehingga siswa akan lebih siap secara fisik dan mental untuk melakukan kegiatan pembelajaran sepakbola selanjutnya.

MEDIKORA Vol.III, No 1, April 2007: 288-302 


\section{Daftar Pustaka}

Agus Mahendra. (2001). Pembelajaran Senam di Sekolah Qasar Sebuah Pendekatan pembinaan Pola Gerak Dasar Dominan. Jakarta: Depdiknas.

Beberapa Hal Penting Mengenai Peregangan. http://mp.brawijaya.ac.id/art/04-artikel3.php

Gabbard, Carl. et al. 1987. Physical Education for Children: Building the Foundation. New Jersey: Prentice-Hall, Inc.

Gusril. 2004. Efektivitas Ancangan Modifikasi Olahraga ke dalam Penjas. Jurnal Nasional Penjas dan Ilmu Keolahragaan. Volume 3, Nomor I, April.

Joe Luxbacher. (2004). Sepakbola: Taktik dan Teknik Bermain. Jakarta: Raja Grafindo Persada.

Len Kravits. (1997). Bugar Total. Jakarta: PT. Raja Grafindo Persada.

Olahraga perlu Pemanasan. http://victorhealth.blogspot.com/2008/10/olahraga-perlupemanasan-dan.html.

Pangrazi, Daur P. dan Daur, Victor P. 1989. Dynamic Physical Education for Elementary School Children. (Nine Edition). USA: Macmillan Publishing Company.

Sukadiyanto. (2005). Pengantar Teori dan Metodologi Melatih Fisik. Yogyakarta: FIK UNY.

Tjaliek Soegiardo. (1992). Ilmu Faa PGSD Penjas. Jakarta: Depdikbud.

Yuanita Nasution dan Ariani Abriani. 2000. Aspek Psikologis dalam Pemanduan Bakat Olahraga. Jakarta: KONI. 